\title{
Reciprocating Wear Behavior of Ductile Cast Iron Modified by Pulse Plasma Technology
}

\author{
A. AydaY* And M. Durman \\ Sakarya University, Faculty of Engineering, Department of Metallurgical and Materials Engineering \\ Sakarya, 54187, Turkey
}

\begin{abstract}
Wear resistance of ductile iron can be improved through different surface engineering techniques, each having some limitations and drawbacks. Recently, a new method called pulse plasma technology has been introduced, which through local reinforcement with inserts improves wear resistance of ductile iron without compromising other properties. This paper deals with the improvement of the wear resistance of ductile iron surface modified by pulse plasma technology using a tungsten electrode. The surfaces of the samples were treated by $\mathrm{C}_{3} \mathrm{H}_{8}$, air, and oxygen gases. The surface morphology and the phase structure in the near surface region of original and treated samples were analyzed with optic microscope, scanning electron microscope and energy-dispersive spectroscopy. The surface properties were evaluated by measuring the microhardness, wear properties and friction coefficient, as well as the elemental depth profiles and chemical composition of the modified layer. It was found that the microhardness of the treated samples was much higher. The tribological resistances were also significantly improved, as confirmed by the reduced friction coefficient and wear track width. This improvement can be attributed to the diffusion of tungsten on the surface layer.
\end{abstract}

DOI: $10.12693 /$ APhysPolA.125.189

PACS: 81.65.-b, 68.35.bd, 81.40.Pq

\section{Introduction}

Ductile irons have become a very popular topic as a result of their distinctive combination of high strength and toughness. This interest is to be expected because of the favorable combination of strength, toughness, and wear resistance that can be obtained from various grades of ductile iron compared with the conventional grades of metal alloys $[1,2]$.

Attempts to increase the wear resistance of ductile iron by application of surface hardening techniques are successful. But some disadvantages and cost limit these techniques [3-5]. That is why an alternative surface treatment pulse plasma technology (PPT), which is cheap, has rapid heating rate and no limitation on toll size, is presently used. PPT is characterized by several process parameters: capacity, electrode, pulse number and distance between nozzle to sample. All these parameters are strongly correlated to each other and affect the final hardening and modification layer thickness results; hence, process modeling seems to be a good approach to the process optimization $[6,7]$.

The aim of this paper is to study the microstructure behavior of PPT treated ductile iron specimens. Hardness and tribological and wear behaviors before and after treatment were investigated.

\section{Experimental procedure}

Specimens of the ductile iron were produced in a commercial foundry. The chemical composition of the iron

*corresponding author; e-mail: aayday@sakarya.edu.tr is given in Table I. Hardness of the ductile iron as-cast microstructure was equal to $280 \mathrm{HV}_{0.05}$. Specimens of as-cast ductile iron were pulse plasma treated in accordance with the optimized experiment plan shown in Table II.

TABLE I

Chemical composition of the cast iron used (wt.\%)

\begin{tabular}{c|c|c|c|c|c|c|c}
\hline \hline $\mathrm{C}$ & $\mathrm{Si}$ & $\mathrm{Mn}$ & $\mathrm{Cu}$ & $\mathrm{Cr}$ & $\mathrm{Mg}$ & $\mathrm{P}$ & $\mathrm{S}$ \\
\hline 3.22 & 2.51 & 0.104 & 0.768 & 0.044 & 0.041 & 0.06 & 0.0111
\end{tabular}

TABLE II

Pulse plasma parameters ( $H$ - nozzle-samples distance, $h$ - electrode-nozzle distance, $C$ - capacity, $n$ - applied pulse).

\begin{tabular}{c|c|c|c|c|c}
\hline \hline Samples & $H[\mathrm{~mm}]$ & $h[\mathrm{~mm}]$ & Electrode & $C[\mu \mathrm{F}]$ & $n$ \\
\hline G10 & 60 & 10 & W & 800 & 10 \\
G15 & 60 & 10 & W & 800 & 15 \\
G20 & 60 & 10 & W & 800 & 20
\end{tabular}

PPT modified specimens were metallographically analyzed and a profile of microhardness of the hardened surfaces was determined. Wear tests were performed on untreated specimen and pulse plasma modified specimens to determine the wear resistance. All wear tests were carried out under dry sliding conditions at ambient temperature using a ball-on-disc friction and wear test machine. Tests were performed with nominal load of $1 \mathrm{~N}$ and a sliding speed of $0.1 \mathrm{~m} / \mathrm{s}$ for a total sliding distance of $200 \mathrm{~m}$. After the wear tests, width of wear scars were examined by scanning electron microscopy (SEM) and calculated the wear rate by the program of CSM tribometer to examine whether any change in wear behavior occurred as a result of the applied surface treatment. 


\section{Results and discussion}

Figure $1 \mathrm{a}-\mathrm{c}$ shows microstructure of modified ductile iron. It shows the formation of the hardened layer at the pulse number range 10 to 20 . G10 specimen, the modified layer shows a shallow structure. The hardness of G10 sample modified layer was maximum $515 \mathrm{HV}_{0.05}$ by the 10 number of pulse. The modified layer starts to grow into a finger at 15 pulse number; modification layer thickness was increased with increasing pulse number (Fig. 1b). The G20 sample, modified by 20 number of pulse, layer was thickest and uniform on surface. The hardness of the modified layer was maximum $729 \mathrm{HV}_{0.05}$.

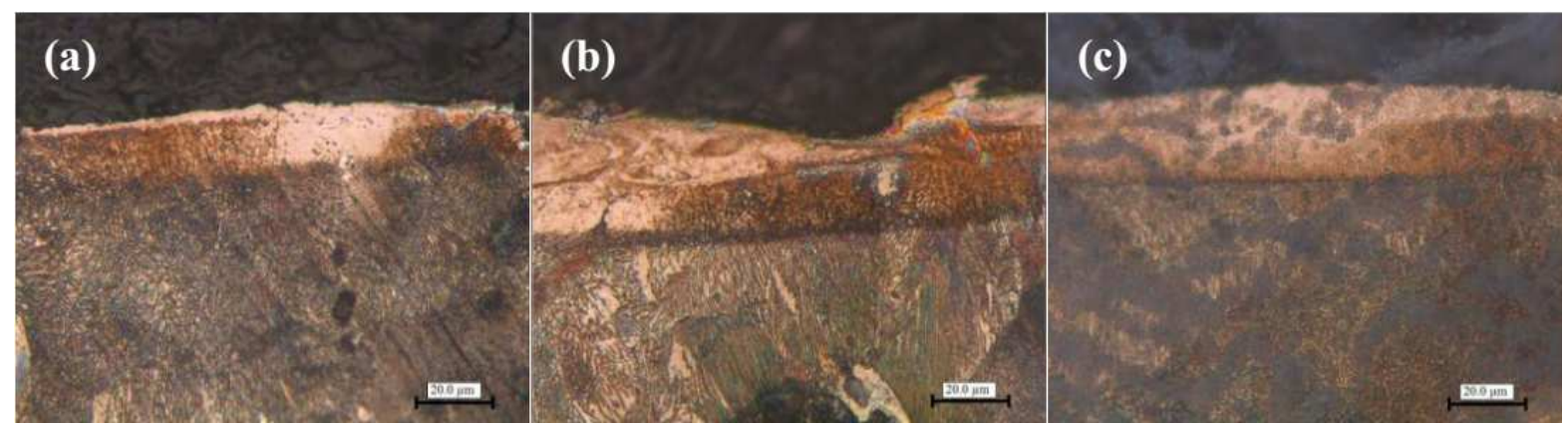

Fig. 1. Cross-sectional optical micrographs of the pulse-plasma modified ductile iron: (a) G10, (b) G15, (c) G20.

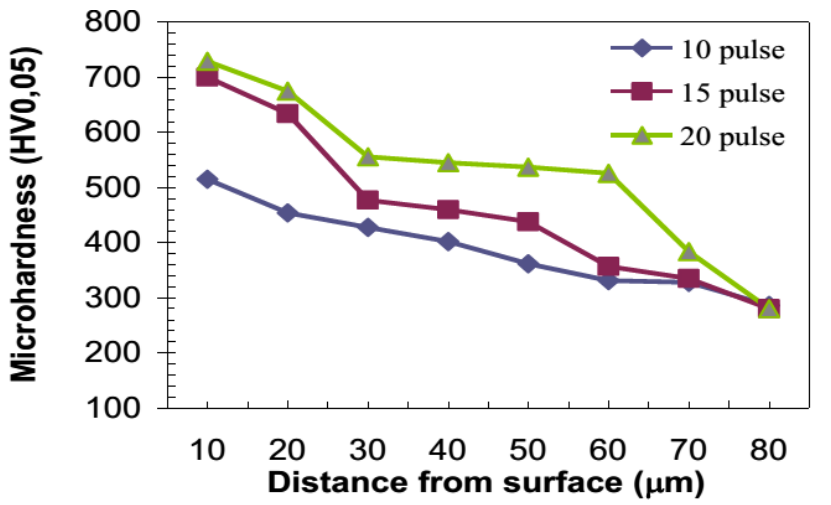

Fig. 2. Microhardness value of samples.

The cross section distribution of microhardness is shown in Fig. 2. The hardness profile curve displayed a consistent trend for all pulse number. The cross-sectional microhardness increases with increasing pulse number. A rise in treatment from 10 to 20 pulse shows a significant increase in hardness of an additional $200 \mathrm{HV}$ as shown in Fig. 2. It is clear that the hardness of the pulse plasma treated layer is significantly higher than that of the substrate due to the presence of tungsten element confirmed by EDS (Fig. 3). Thus, hardening of the layer is attributed to the saturation of $\mathrm{W}$.

Figure $4 \mathrm{a}-\mathrm{b}$ shows the wear coefficients and wear rates for the untreated, G10 and G20 specimens under $1 \mathrm{~N}$ load and at sliding speed of $0.1 \mathrm{~m} / \mathrm{s}$. It can be seen that changing the pulse number also causes change in the contact conditions confirmed by the coefficient of friction (C.O.F.). It can be seen that PPT causes reduction in wear coefficients and wear rates as compared to untreated specimen. The microhardness values of the modified samples indicate that pulse plasma treating has the potential to offer good wear resistance to the ductile iron by increasing their hardness.

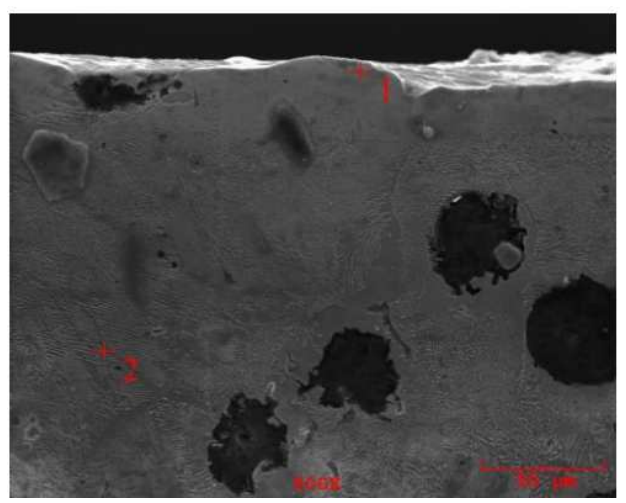

Fig. 3. EDS analysis of the G10.
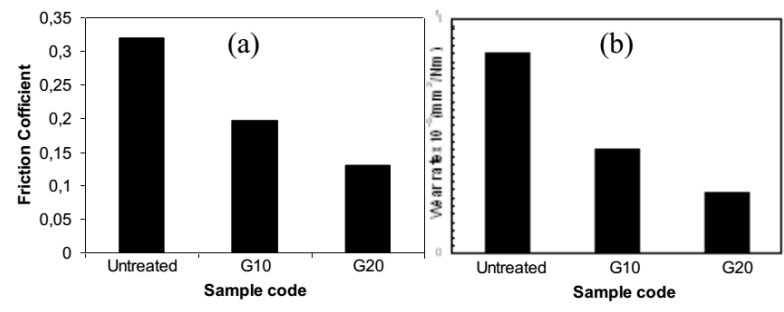

Fig. 4. (a) C.O.F. of the untreated, G10, G20 samples, (b) wear rates of the untreated, G10, G20 samples.

Decreasing the number of pulse was most effective on wear resistance, because the $\mathrm{W}$ ratio was changed within the PPT conditions. Worn surfaces of the ductile iron with pulse number 10 (G10) and pulse number 20 (G20) are shown in Fig. 5. A severe adhesive wear was observed on the G10 specimens as revealed in Fig. 5a. Accordingly, the amount of the debris removed from the G10 specimen toward the sides of the wear track was much more than G20 specimen. Besides, the increasing pulse number reduces both the width of the wear track and the 


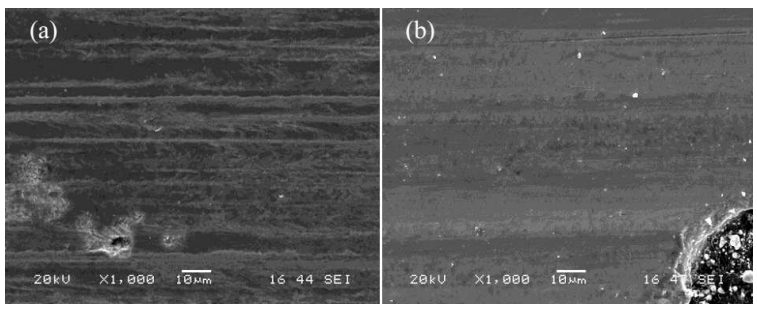

Fig. 5. SEM micrographs showing the worn surface morphologies of (a) G10 and (b) G20.

amount of the debris removed. The wear phenomenon occurred uniformly at the PPT modified with maximum pulse number specimen (Fig. 5b). It can be seen that the worn surfaces are comparatively smooth with little ploughing and small debris.

\section{Conclusion}

The paper has demonstrated that PPT process can be used for surface modification of ductile iron. The hardness of the pulse plasma treated layer was significantly higher than that of the substrate due to the presence of tungsten element. The average hardness in the modified layer of G10, G15, G20 is 515, 700, and $729 \mathrm{HV}_{0.05}$, respectively, and was higher than that of the untreated sample $\left(280 \mathrm{HV}_{0.05}\right)$. The C.O.F. and the nature of wear grooves depended on the hardness of the surface. W reinforced surface provides better wear resistance of ductile iron, at the same improving its friction properties.

\section{References}

[1] X. Nie, L. Wang, Z.C. Yao, L. Zhang, F. Cheng, Surf. Coat. Technol. 200, 1745 (2005).

[2] M. Shamanian, S.M.R. Mousavi Abarghouie, S.R. Mousavi Pour, Mater. Design 31, 2760 (2010).

[3] R. Arabi Jeshvaghani, M. Shamanian, M. Jaberzadeh, Mater. Design 32, 2028 (2011).

[4] C. Soriano, J. Leunda, J. Lambarri, V. García Navas, C. Sanz, Appl. Surf. Sci. 257, 7101 (2011).

[5] B. Podgornik, J. Vizintin, I. Thorbjornsson, B. Johannesson, J.T. Thorgrimsson, M. Martinez Celis, N. Valle, Wear 274, 267 (2012).

[6] Yu.N. Tyurin, A.D. Pogrebnjak, Surf. Coat. Technol. 111, 269 (1999).

[7] Y.Y. Özbek, M. Durman, H. Akbulut, Tribol. Trans. 52, 213 (2009). 